\title{
AVALIAÇÃO DO POTENCIAL DA FIBRA DO SISAL COMO SUBSTRATO EM BIOPROCESSOS
}

\author{
W. A. DA COSTA ${ }^{1}$, E. A. DOS SANTOS ${ }^{1}$, F. L. H. DA $\operatorname{SILVA}^{1}$, J. D. $\operatorname{SILVA}^{2}$ e M. M. DA \\ CONCEIÇÃO ${ }^{3}$. \\ ${ }^{1}$ Universidade Federal da Paraíba, Departamento de Engenharia Química \\ ${ }^{2}$ Universidade Federal da Paraíba, Departamento de Engenharia de Alimentos \\ ${ }^{3}$ Universidade Federal da Paraíba, Departamento de Química \\ E-mail para contato: willyam.costaa@gmail.com
}

\begin{abstract}
RESUMO - Tendo em vista a grande relevância que os produtos de origem microbiológica vêm tomando nas ultimas décadas, o presente artigo estudou a viabilidade do uso da fibra do sisal como substrato em bioprocessos. A caracterização do material mostrou que o mesmo apresenta uma composição de $51,00 \%$ de celulose, $17,64 \%$ de hemicelulose e 12,26\% de Lignina. Na etapa de pré-tratamento ácido, a condição que forneceu uma maior produção de açúcares fermentescíveis foi a realizada com 3,5\% de $\mathrm{H}_{2} \mathrm{SO}_{4}$ e $2 \mathrm{~h}$ de reação em autoclave, a uma proporção de material sólido/solução de 1:10 (m/v).
\end{abstract}

\section{INTRODUÇÃO}

Dentro do contexto da dinâmica socioeconômica da indústria mundial, é de vital importância o uso de resíduos agroindustriais como matéria-prima para produção de produtos de valor agregado (valorização dos resíduos), tornando-se evidente a necessidade de investimento na produção de bioprodutos.

À medida que o conceito de sustentabilidade vem sendo difundido no meio industrial, o emprego de resíduos como matéria-prima para a produção de compostos por fermentação vem se consolidado cada vez mais. Esses resíduos apresentam uma composição bem característica, são os chamados materiais lignocelulósicos, pois os mesmo possuem em sua composição bioquímica basicamente: celulose, lignina e hemicelulose em proporções que variam para cada tipo de material e época/local de cultivo (CANILHA, et al., 2012).

Um bom representante dessa classe de materiais é o Agave sisalana, que é de grande relevância econômica em regiões áridas como o Nordeste brasileiro, concentrando-se sua exploração no interior dos Estados da Bahia (87\%), Paraíba $(7,4 \%)$ e Rio Grande do Norte $(5,2 \%)$. (DA SILVA, et al., 2008).

A utilização da fibra do sisal como matéria para a produção via ação microbiológica de compostos bioativos se mostra viável tendo como base a proporção dos polímeros orgânicos que a compõem, sendo as mesmas aproximadamente: $78 \%$ celulose, $10 \%$ hemicelulose e $9 \%$ de lignina e $2 \%$ de cinzas (MARTIN, et al., 2009). 
O objetivo deste trabalho foi avaliar o potencial emprego da fibra do sisal como substrato na produção de compostos bioativos, produzidos por via microbiana, através da caracterização do material e estudo do comportamento da mesma frente às condições de prétratamento ácido.

\section{MATERIAIS E MÉTODOS}

\subsection{Caracterização do material lignocelulósico}

A metodologia empregada na caracterização do material foi proposta por Morais, Rosa e Marconcine (2010). Foram realizadas análises de determinação dos teores de umidade, cinzas, extrativos, lignina, holocelulose e alfacelulose. Todos os ensaios foram realizados em triplicata, objetivando assim a mitigação de eventuais erros.

\subsection{Caracterização do material por termogravimetria}

A caracterização termogravimétrica foi realizada em uma balança termoanalítica (TGA Modelo: Q50), no Laboratório de Carvão Ativo, no Centro de Tecnologia/UFPB.

\subsection{Avaliação do comportamento do material frente o pré-tratamento ácido}

No estudo do comportamento do material ao ser submetido a um pré-tratamento ácido, foi avaliado um conjunto de tratamentos, onde dois parâmetros foram avaliados, sendo eles: $\mathrm{H}_{2} \mathrm{SO}_{4}$ e o tempo de reação. $\mathrm{O}$ procedimento foi conduzido em autoclave a uma temperatura de $120{ }^{\circ} \mathrm{C}$ na proporção de 1:10 (m/v) em Erlenmeyers de $300 \mathrm{~mL}$. As concentrações de ácido avaliadas foram de $1,5 \%, 3,5 \%$ e 5,5\% (v/v) e o tempo de reação variou de $1 \mathrm{~h}$ a $3 \mathrm{~h}$. O licor produzido foi então analisado por cromatografia liquida de alta performance (HPLC) visando então a caracterização do mesmo.

\section{RESULTADOS E DISCUSSÕES}

\subsection{Caracterização lignocelulósica}

Na Tabela 1 estão dispostos os resultados obtidos para a caracterização lignocelulósica do material:

Tabela 1 - Teores obtidos da caracterização lignocelulósica

\begin{tabular}{ccc}
\hline Componente & Teor (\%) & $\begin{array}{c}\text { Lima et al. (2013) } \\
(\%)\end{array}$ \\
\hline Umidade & 6,71 & 5,7 \\
Extrativos & 3,34 & 5,8 \\
Holocelulose & 81,30 & 72,1 \\
Lignina & 12,26 & 13,5 \\
\hline
\end{tabular}




\begin{tabular}{ccc}
\hline $\boldsymbol{\alpha}$ - Celulose & 51,00 & 52,8 \\
\hline Cinzas & 1,23 & 2,1 \\
\hline Hemicelulose & 17,64 & 19,3 \\
\hline
\end{tabular}

O resultado obtido mostrou-se coerente com o que vem sendo reportado pela literatura especializada. Do ponto de vista comparativo, pode-se dizer que a fibra do sisal se destaca de outras matérias-primas utilizadas na produção como substrato em bioprocessos, isso se deve ao fato da mesma possuir um teor de lignina inferior ao apresentado por esses, o que viabiliza uma eventual intervenção ácida objetivando a quebra dos polímeros estruturais, celulose e hemicelulose, em açúcares fermentescíveis. Tais afirmações podem ser verificadas comparando-se tais teores aqui determinados com os apresentados por Lima et al. (2015) para o bagaço do pedúnculo do Caju e por Canilha et al. (2012), para o bagaço da cana de açúcar, mostrados na Tabela 2.

Tabela 2 - Comparação entre os teores de lignina e hemicelululose em diferentes materiais

\begin{tabular}{cccc}
\hline Componente & $\begin{array}{c}\text { Fibra do Sisal } \\
(\boldsymbol{\%})\end{array}$ & $\begin{array}{c}\text { Bagaço do Caju (\%) } \\
\text { (Lima et al., 2015) }\end{array}$ & $\begin{array}{c}\text { Bagaço de Cana (\%) } \\
\text { (Canilha et al., 2012) }\end{array}$ \\
\hline Lignina & 12,26 & 23,7 & $19,01-32,4$ \\
Hemicelulose & 17,64 & 15,1 & $22,7-27,0$ \\
\hline
\end{tabular}

\subsection{Caracterização termogravimétrica}

A curva termogravimétrica (TG), bem como a sua derivada (DTG), estão mostradas na Figura 1, onde tem-se a presença de três patamares durante a execução do ensaio, o primeiro corresponde à hidratação do material e se deu na faixa térmica que vai do inicio da caracterização até aproximadamente $100^{\circ} \mathrm{C}$, evidenciando um percentual de transferência de massa de $10,01 \%$. O Segundo patamar ocorreu na faixa de $300-410^{\circ} \mathrm{C}$ denotando um percentual total de $61,91 \%$, o mesmo corresponde à decomposição da hemicelulose e da celulose. Por fim, o terceiro patamar, que corresponde à degeneração da celulose e lignina, mostrou que após $500^{\circ} \mathrm{C}$ todos os polímeros da estrutura vegetal estavam decompostos evidenciando um percentual de 10,77\%. Em geral, o comportamento está adequado com o reportado na literatura (LIMA et al., 2013) e respalda o que foi obtido na análise lignocelulósica. 
Figura 1 - Curvas TG e DTG.

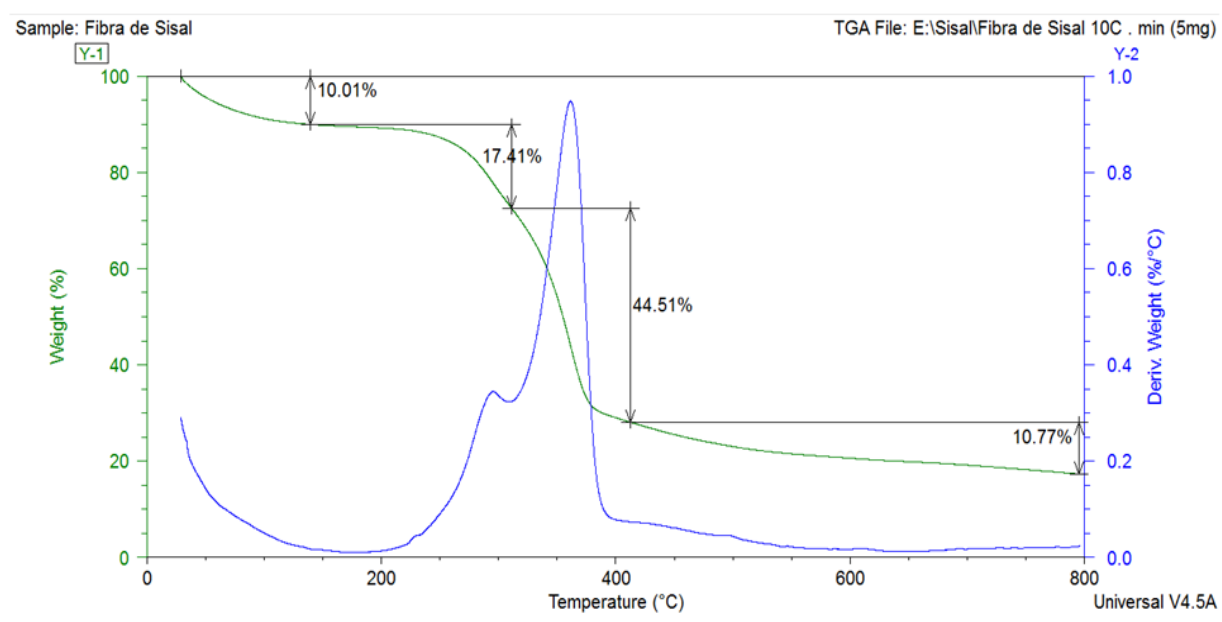

\subsection{Avaliação do comportamento frente ao pré-tratamento ácido}

O objetivo da realização do pré-tratamento ácido foi proporcionar uma desestruturação dos polímeros que compõem o material fazendo com que os mesmos sejam degenerados às suas unidades monoméricas, monossacarídeos. Os resultados obtidos para as condições avaliadas estão dispostos na Tabela 3.

Tabela 3 - Resultados do pré-tratamento ácido

\begin{tabular}{lccccc}
\hline Tratamento & $\begin{array}{c}\text { Celobiose } \\
(\mathbf{g} / \mathbf{L})\end{array}$ & $\begin{array}{c}\text { Glicose } \\
(\mathrm{g} / \mathbf{L})\end{array}$ & $\begin{array}{c}\text { Xilose } \\
(\mathbf{g} / \mathbf{L})\end{array}$ & $\begin{array}{c}\text { Arabinose } \\
(\mathbf{g} / \mathbf{L})\end{array}$ & $\begin{array}{c}\text { AR } \\
(\mathrm{g} / \mathbf{L})\end{array}$ \\
\hline $\mathbf{( 1 ) 1 , 5 \% - 1 h}$ & 0 & 0,7 & 11,8 & 0 & 12,5 \\
$\mathbf{( 2 ) 5 , 5 \% - 3 h}$ & 0,6 & 2,5 & 16,2 & 0 & 18,7 \\
$\mathbf{( 3 ) 3 , 5 \% - 2 h}$ & 5,1 & 2,4 & 16,8 & 2,6 & 21,8 \\
\hline
\end{tabular}

$\mathrm{AR}=$ açúcares redutores.

A maior concentração de açúcares redutores obtida nas condições estudadas foi de 21,8 g/L. Esse resultado está próximo do obtido por Roberto e Mussatto (2004), 22,7 g/L, para um hidrolisado obtido sob as mesmas condições termodinâmicas em um reator de aço inox utilizando palha de arroz como matriz lignocelulósica. Já Cassales (2010) obteve, em sua melhor condição hidrolítica, um teor de açúcares redutores equivalente a 12,3 g/L utilizando como material a ser hidrolisado a casca de soja. O que enfatiza a boa aplicabilidade da fibra do Agave como matriz fornecedora de monossacarídeos, uma vez esses açúcares são utilizados como fonte de carbono pelos microrganismos em uma vasta gama de bioprocessos industriais.

Uma observação sobre esses resultados mostra que ao submeter o material às condições extremas (1), o mesmo não gerou uma melhor concentração de açúcares redutores quando comparado com a situação (2), mais branda. Isso se deve ao fato de que em condições muito agressivas à estrutura polimérica/estrutural do material, há a formação de compostos inibidores. Tais inibidores são formados devido às condições que estão associadas ao 
processo, como temperatura elevada e ambiente reacional muito ácido, sendo os principais inibidores gerados durante o processamento hidrolítico: o ácido acético, o furfural, formado a partir da degradação da xilose e arabinose, e o 5-hidroximetilfurfural, oriundo principalmente da degeneração da glicose (ROCHA, 2010).

\section{CONCLUSÃO}

Os resultados obtidos nesse trabalho mostraram que de fato há uma grande viabilidade em se empregar a fibra do sisal como substrato na produção biotecnológica de compostos de interesse industrial e comercial uma vez que tal material apresentou um excelente teor de polímeros estruturais que são fontes de açúcares fermentescíveis e uma boa resposta ao processo hidrolítico em meio ácido.

\section{REFERENCIAS}

CANILHA, L. et al. Bioconversion of Sugarcane Biomass into Ethanol: An Overview about composition, Pretreatment methods, Detoxification of hydrolysates, Enzymatic Saccharification and Ethanol fermentation. Journal of Biomedicine and biotechnology, p. 1-15, out 2012.

CASSALES, A. R. Otimização da hidrólise da casca de soja (Glycine max) e a avaliação da capacidade de produção de xilitol e etanol por microrganismos sobre este hidrolisado. Porto Alegre:UFRGS, 2010. 138 p. Dissertação (Mestrado) - Programa de PósGraduação em Ciência e Tecnologia de Alimentos, Universidade Federal do Rio Grande Do Sul, Porto Alegre, 2010.

DA SILVA, O. R. R. F. et al. Cultivo do sisal no nordeste brasileiro. EMBRAPA. Campina Grande, p. 1-23, jul, 2008.

LIMA, C. S. S. et al. Characterization of acid hydrolysis of sisal. Applied Energy, v. 102, p. 254-259, 2013.

LIMA, E. E. et al. Produção de Etanol de segunda geração proveniente do bagaço do pedúnculo do caju. Revista Caatinga, Mossoró, v. 28, n. 2, p. 26-35, abr-jun 2015.

MARTIN et al., Caracterização química e estrutural de fibra de sisal da variedade Agave sisalana. Polímeros: Ciência e Tecnologia, v.19 n.1 p.40-46, São Paulo, 2009.

MORAIS, J. P. S.; ROSA, M. de F.; MARCONCINI, J. M. Procedimento para análise lignocelulósica. Campina Grande: Embrapa Agroindústria Tropical, 2010.

ROBERTO, I. C.; MUSSATTO, S. I. Avaliação de diferentes tipos de carvão ativo na destoxificação de hidrolisado de palha de arroz para produção de xilitol. Food Science and Technology, v. 24, n. 1, Campinas, 2004. 
ROCHA, M. V. P. Produção de Bioetanol a partir de pedúnculo de caju (Anacardium occidentale L.) por fermentação submersa. NATAL: UFRN, 2010. 213 p. Tese (Doutorado) - Programa de Pós-Graduação em Engenharia Química, Universidade Federal do Rio Grande do Norte, Natal, 2010. 